\title{
LXXII. An experimental inquiry into the nature of the radiant heating effects from terrestrial sources
}

\section{Baden Powell M.A. F.R.S.}

To cite this article: Baden Powell M.A. F.R.S. (1825) LXXII. An experimental inquiry into the nature of the radiant heating effects from terrestrial sources, Philosophical Magazine Series 1 , 65:326, 437-447, DOI: $10.1080 / 14786442508652896$

To link to this article: http://dx.doi.org/10.1080/14786442508652896

册 Published online: 27 Jul 2009.

Submit your article to this journal $₫$

Џ Article views: 3

Q View related articles 둔 
longs to those groups, which, with a free hallux, legs placed within the equilibrium of the body, and inferior powers of swimming and none of diving, affect the neighbourhood of fresh waters, feed occasionally on land, and as such form part of the aberrant subdivisions of the Natatorial Order. It is evidently remote from $A$. boschas, of which the middle tailfeathers also appear the longest, but which are invariably curved upwards. While it may also be perceived to hold a different station from $A$. acuta, which, although closely allied to the same group, yet from its long neck and legs is found to stand at that remote end of it where it is connected with the Anseres, the next conterminous division of the family. Its nearest affinity among the European species is to the $A$. circia, Gmel., and A. crecca, Linn.*

The appearance of this species in the British Islands seems of rare occurrence; two instances only of the kind having been recorded. These most probably are to be attributed to some extraordinary accident or stress of weather.

LXXII. An experimental Inquiry into the Nature of the radiant heating Effects from terrestrial Sources. By BADEN Poweld, M.A. F.R.S., of Oriel College, Oxford.†

(1.) THE nature of the heating effect emanating from $l u$ minous hot bodies has been distinctly shown to be, in many particulars, very different from that evolved from non-luminous sources; but the ideas commonly entertained on the subject are far from being precise and distinct. To gain, if possible, some ground for establishing more clear views, is the object of the following inquiries.

(2.) Professor Leslie, in his well known and elegant experiments (Inquiry concerning Heat, \&c, chap. iii.) has fully established the theory of the effect of screens on radiant heat; and these effects give some of the most important criteria for examining the nature of radiating agents.

Those experiments apply only to the heat evolved from a non-luminous source. It therefore naturally becomes the subject in question, Whether the interceptive power of glass is not limited to a certain temperature, or state, of the radiating source: and to this point accordingly the attention of several eminent observers has been directed in many well known investigations, among which those of $M$. De La Roche are justly regarded as the most important and complete. In these ex-

* The Querquestula circia and Q. crecer of modern ornithologists.

+ From the Philosophical Transactions for 3825 . Part $I$.

perinents 


\subsection{Mr. B. Powell's experimental Inquiry into the Nature}

periments it appears, that a greater effect is produced on a blackened thermometer when a glass screen is interposed, in proportion as the body under trial approaches nearer its point of luminosity, or becomes more intensely luminous. (Biot, Traité de Phys. tom. iv. p. 638. Ann. of Philos. O.S. vol. ii. p. 163.)

Both M. De La Roche and M. Biot (see Biot, iv. 612) seem disposed to view the results obtained by the former, upon the supposition of one simple agent, the principle both of light and heat. This is at first radiated as heat; at a certain point it_begins to assume the form of light, when the interceptive power of glass decreases in proportion to the increase of luminosity.

(3.) As long as the hot body continues below the temperature of luminosity, the partial or total interception of the effect is precisely the same phænomenon as that described by Professor Leslie in his experiments on screens, and explicable in the same way. (Phil. Trans. 1816, Part I. "On new Properties of Heat," Prop. 40.) And the apparent transmission of a portion of the effect must be referred to the same principle, as is clearly shown by Dr. Brewster, who has established, apparently beyond contradiction, the impermeability of glass to simple radiant heat upon quite independent principles.

(4.) Above the temperature of luminosity we must have recourse to further considerations. The hypothesis of MM. De La Roche and Biot appears to be nearly the same as that of Professor Leslie. (Inquiry, p. 162.) And it certainly has the merit of simplicity and satisfactory explanation of the phænomena. But it is an opinion which has not received direct proof; and it is also obvious that the phænomena may be explained without it; for we may just as well account for the facts, by supposing two distinct heating influences, one associated in some very close way with the rays of light, carried as it were by them through a glass screen without heating it; the other being merely simple radiant heat, affected by the screen exactly as the radiant heat from a non-luminous body.

(5.) In order to ascertain which of these suppositions is true, it will not be sufficient to observe the effects produced by the intervention of a screen alone. We must combine this method with an examination of the relations of different sorts of heat to surfaces. These relations have been shown to differ according as the body is luminous, or not: in the one case, the direct heat affects bodies in proportion to the darkness of their colour, without regard to the texture of their surface; in the other, the magnitude of the effect depends solely on the absorptive texture, without reference to colour. I use the term " absorptive 
" absorptive texture," to signify that peculiar state of division in the particles of the surface, which has been shown by Professor Leslie and others to be most susceptible of the influence of simple radiant heat, and always to give a proportionally greater radiating power.

The question then is entirely one of facts, and involves no hypothesis as to the nature either of light or of heat. The object is simply to ascertain by experiment, whether, of the total heating effect radiated from a luminous hot body, the portion intercepted by a transparent screen is of the same nature as, or different from, the part transmitted in its relations to the surfaces on which it acts.

(6.) In conformity with this view of the object proposed, the general principle of the following experiments is this: taking different luminous hot bodies, to expose to their influence two thermometers, presenting one, a smooth black surface, the other an absorptive white one; thus obtaining the ratio of the total direct effect on the two, we may compare it with the ratio similarly observed when a transparent screen is interposed.

(7). This principle of experimenting was applied with one or two variations; and though in the abstract sufficiently simple, it will in practice require an attention to several considerations. I shall therefore proceed in the first instance to the detail of the different particulars; then give the results of the experiments in a tabular form; and lastly, recapitulate the conclusions and make a few general remarks.

I. (8.) In the following set of experiments two common thermometers were employed. The diameters of their bulbs were, thermometer A, 0.6 inch.; $B \quad 0.55$. A was coated with a wash of chalk and water, and B with Indian ink.

In order to compare the effects to be observed with those of simple radiant heat, I ascertained the ratio of the effects of the latter on the two bulbs thus coated, by a few preliminary trials, and found it to be very nearly one of equality, or perhaps, the effect of the white rather greater than that of the black.

The two thermometers were graduated to quarters of centigrade degrees; and were both fixed on one mounting, with their bulbs detached about one inch from its lowest part, and at the distance of about three quarters of an inch from each other.

(9.) In the $2 \mathrm{~d}$ set of experiments they were fixed into the top of a box, the front of which was open, so that the glass screen could be applied to it or not, as required. When the screen was not used the box would acquire more heat, and radiate it to the bulbs in a small degree; which affecting them 


\section{Mr. B. Powell's experimental Inquiry into the Natuie}

in the inverse ratio of their diameters, would diminish the ratio of their risings. That this diminution was very trifling, and not at all sufficient to account for the observed difference of ratio will be evident, because the 1st set was made without employing the box, the thermometers being suspended at a distance from any object which could radiate heat to them; and in this set the difference of ratio is quite as conspicuous. This remark applies likewise to the possible communication of heat by the air.

(10.) We must also take into consideration the effect due to the glass screen. When we consider the two bulbs as heated only by that part of the radiation which is tranismitted through the screen, the screen may be regarded simply as a third body placed near the two bulbs; and whether it possesses a higher or a lower temperature, there will be a tendency to bring all three to an equality in proportion to the difference of temperature, and in the bulbs, dependent on their diameters modified by the state of their surfaces. This effect arises from simple radiant heat; whilst that derived from the luminous hot body, is evidently following a different law with regard to the surfaces. It will easily follow, from what has been already shown, that such a secondary heating effect will be of a kind tending to diminish the ratio otherwise obtaining between the effects on the two bulbs. If the effect were of a cooling nature, the same thing would also take place; for I ascertained that the radiating powers of the coatings employed, deduced from the observed rates of cooling, were in a ratio which happened to be almost exactly the inverse of that of the diameters; but this effect is probably always small; and I have roughly allowed for it, as will be seen immediately; taking the temperature of the screen by a small thermometer having its bulb in contact with the central part of the surface.

II. (11.) I now proceed to state the results, which will be most conveniently exhibited in a tabular form.

1st Set. Incandescent iron. Distance 7 inches.

Glass Screen.

\begin{tabular}{|c|c|c|}
\hline Experiment. & \multicolumn{2}{|c|}{$\begin{array}{c}\text { Rise of Thermometer } \\
\text { in 1 min. centigrade. }\end{array}$} \\
\cline { 2 - 4 } & A. white. & B. black. \\
\hline 1 & $1 \cdot 25$ & $2 \cdot 5$ \\
2 & $1 \cdot 25$ & $3 \cdot$ \\
\hline Mean & $1 \cdot 25$ & $2 \cdot 75$ \\
\hline $\left.\begin{array}{l}\text { Allowing for the } \\
\text { screen as below }\end{array}\right\}$ & $1 \cdot$ & $2 \cdot 5$ \\
\hline
\end{tabular}


of the radiant heating Effects from terrestrial Sources. $\quad 441$ No Screen.

\begin{tabular}{|c|c|c|}
\hline \multirow{2}{*}{ Experiment. } & \multicolumn{2}{|c|}{ Rise Therm. 1 min. cent } \\
\hline & A. white. & B. black. \\
\hline 1 & $7 \cdot 5$ & $9 \cdot 75$ \\
\hline 2 & $6 \cdot 5$ & $7 \cdot 75$ \\
\hline Mean & $7^{\circ}$ & $8 \cdot 75$ \\
\hline $\begin{array}{l}\text { Difference of ex } \\
\text { and screened } r\end{array}$ & 6. & $6 \cdot 25$ \\
\hline
\end{tabular}

(12.) Argand lamp without its chimney. Distance 3 inches. Glass Screen.

\begin{tabular}{|c|c|c|}
\hline \multirow[t]{2}{*}{ Experiment. } & \multicolumn{2}{|c|}{$\begin{array}{l}\text { Rise of Thermometers } \\
\text { in } 1 \text { min. centigrade. }\end{array}$} \\
\hline & A. white. & B. black. \\
\hline 1 & .75 & $1 \cdot 75$ \\
\hline 2 & .5 & $2 \cdot 25$ \\
\hline 3 & $\cdot 75$ & $2 \cdot 25$ \\
\hline Mean & .66 & $2 \cdot 08$ \\
\hline $\begin{array}{l}\text { Allowing for the } \\
\text { screen } . \quad \text {. }\end{array}$ & $\cdot 41$ & 1.83 \\
\hline \multicolumn{3}{|c|}{ No Screen. } \\
\hline$\overline{1}$ & $1 \cdot 75$ & $3 \cdot 5$ \\
\hline 2 & $1 \cdot 75$ & $3 \cdot 25$ \\
\hline 3 & 2 & $3 \cdot 5$ \\
\hline \multicolumn{2}{|c|}{ Mean } & $3 \cdot 4 \cdot 1$ \\
\hline $\begin{array}{l}\text { Difference of exposed } \\
\text { and screened results }\end{array}$ & \} $1 \cdot 42$ & 1.58 \\
\hline
\end{tabular}

(13). 2nd Set. Incandescent iron. Distance 6 inches. Glass screen 2 inches from bulbs.

\begin{tabular}{|c|c|c|c|c|}
\hline \multirow{2}{*}{ 臱 } & \multirow{2}{*}{$\begin{array}{l}\text { Temperature of Screen } \\
\text { before Experiment by } \\
\text { Thermometer in contact. }\end{array}$} & \multicolumn{2}{|c|}{$\begin{array}{l}\text { Rise of Thermometers } \\
\text { in } 1 \text { min. centigrade. }\end{array}$} & \multirow{2}{*}{$\begin{array}{l}\text { Temperature } \\
\text { of Screen after } \\
\text { Experiment. }\end{array}$} \\
\hline & & A. white. & B. black. & \\
\hline 1 & $16 \cdot 5$ & $1 \cdot 5$ & $1 \cdot 5$ & $25 \cdot 5$ \\
\hline 2 & $16 \cdot 5$ & $\cdot 5$ & $1 \cdot 25$ & 23.75 \\
\hline 3 & $17^{\circ}$ & $\cdot 5$ & $1 \cdot 5$ & $24 \cdot 5$ \\
\hline 4 & 17 & $\cdot 5$ & 1. & $22 \cdot 25$ \\
\hline 5 & $17^{\circ}$ & $\cdot 5$ & $1 \cdot$ & $22 \cdot 25$ \\
\hline \multicolumn{5}{|c|}{ Mean } \\
\hline \multicolumn{5}{|c|}{ Effect of the Screen alone, heated above $25^{\circ}$. } \\
\hline $\begin{array}{l}1 \\
2\end{array}$ & & $\begin{array}{l}.25 \\
.25\end{array}$ & $\begin{array}{l}.25 \\
.25\end{array}$ & \\
\hline The & $\left.\begin{array}{l}\text { former result dimi- } \\
\text { hed for this effect }\end{array}\right\}$ & .35 & 1. & \\
\hline
\end{tabular}


44.2 Mr. B. Powell's experimental Inquiry into the Naturs

Incandescent iron. No Screen.

\begin{tabular}{|c|c|c|c|c|}
\hline \multirow{2}{*}{ 疅 } & \multirow{2}{*}{$\begin{array}{l}\text { Temperature of Screen } \\
\text { before Experiment by } \\
\text { Thermometer in contact }\end{array}$} & \multicolumn{2}{|c|}{$\begin{array}{l}\text { Rise of Thermometers } \\
\text { in } 1 \text { min. centigrade. }\end{array}$} & \multirow{2}{*}{$\begin{array}{l}\text { Temperature } \\
\text { of Screen after } \\
\text { Experiment. }\end{array}$} \\
\hline & & A. white. & B. black. & \\
\hline 1 & & 3 & $3 \cdot 5$ & \\
\hline 2 & & 3. & 4. & \\
\hline 3 & & $2 \cdot 75$ & 3.5 & \\
\hline 4 & & $3 \cdot 3$ & 3.75 & \\
\hline \multirow[t]{2}{*}{5} & & $3 \cdot 3$ & $40^{\circ}$ & \\
\hline & Mean & 2.95 & 3.75 & \\
\hline & $\left.\begin{array}{l}\text { fference of the ex- } \\
\text { osed and screened } \\
\text { esults }\end{array}\right\}$ & $2 \cdot 6$ & $2 \cdot 75$ & \\
\hline
\end{tabular}

(14.) Flame of an Argand lamp without its chimney. Distance 3 inches.

Glass Screen 1.5 inch from bulbs.

\begin{tabular}{|c|c|c|c|c|}
\hline \multirow{2}{*}{ 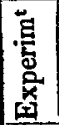 } & \multirow{2}{*}{$\begin{array}{c}\text { Temperature of Screen } \\
\text { before Experiment. }\end{array}$} & \multicolumn{2}{|c|}{$\begin{array}{l}\text { Rise of Thermometers } \\
\text { in } 1 \text { min. centigrade. }\end{array}$} & \multirow{2}{*}{$\begin{array}{l}\text { Temperature } \\
\text { of Screen } \\
\text { after Experi- } \\
\text { ment. }\end{array}$} \\
\hline & & A. white. & B. black. & \\
\hline 1 & \multirow[t]{5}{*}{17} & $1 \cdot 25$ & $2 \cdot 25$ & \multirow[t]{6}{*}{23} \\
\hline 2 & & $1 \cdot 25$ & $2 \cdot 25$ & \\
\hline 3 & & 1.75 & $2 \cdot 25$ & \\
\hline 4 & & $1 \cdot 25$ & $2 \cdot 75$ & \\
\hline 5 & & 1. & $2 \cdot 25$ & \\
\hline \multicolumn{4}{|c|}{ Mean } & \\
\hline \multicolumn{5}{|c|}{ Effect of the Screen alone, heated above $25^{\circ}$. } \\
\hline 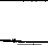 & & .25 & .25 & \\
\hline & $\begin{array}{l}\text { former result dimi- } \\
\text { ished from this effect }\end{array}$ & 1.05 & $2 \cdot 10$ & \\
\hline
\end{tabular}

Lamp. No Screen.

\begin{tabular}{|l|l|l|l|l|}
\hline 1 & & $2 \cdot 25$ & $3 \cdot$ & \\
2 & & $2 \cdot 5$ & $3 \cdot 25$ & \\
3 & & $2 \cdot 25$ & $3 \cdot$ & \\
4 & & $2 \cdot 25$ & $3 \cdot 25$ & \\
5 & & 2.5 & $3 \cdot 5$ & \\
\hline \multicolumn{2}{|c|}{ Mean } & $2 \cdot 35$ & $3 \cdot 2$ \\
\hline Difference of the exposed & $1 \cdot 3$ & $1 \cdot 1$ \\
\hline and screened results . & $1 \cdot 3$ \\
\hline
\end{tabular}

(15.) In 
of the radiant heating Effects from terrestrial Sources. 443

(15.) In these experiments it will be evident upon inspection that the ratio of the effects produced on the white and black bulbs is in every instance considerably greater, when they were affected only by that part of the total heating influence which is transmitted through a transparent screen, than when they were exposed to the whole. This then would indicate, that on the removal of the screen some new heating power was brought into action, which affected the ratio by the addition to each of its terms, of quantities in a ratio expressed by that of the difference of the exposed and screened results above given. This ratio is evidently one differing a little from equality, and agreeing nearly with that of the diameters of the bulbs inversely.

(16.) The experiments now detailed will probably be considered sufficient to substantiate the conclusion; but in researches of this kind, where great numerical precision is unattainable, it seemed desirable to give the experiments that confirmation which they wanted in point of intrinsic accuracy, by frequent repetition and variation. With this view I made a great number of trials with a large differential thermometer: the bulbs were about one inch in diameter, and nearly three inches apart. The bore of the tube was about $\frac{1}{10}$ th of an inch. Many of the experiments made with this instrument I shall not mention, as, although all agreeing to confirm my former conclusions, they were complicated by several unnecessary conditions.

(17.) In order to obtain results in the most simple manner, it was desirable to get rid of any action on one of the bulbs, and to expose only the other; the instrument thus acting simply as an air-thermometer. The effects on each bulb, one being painted with Indian ink, and the other coated with white silk pasted on, when exposed, might thus be compared with those through a glass screen. I first tried the experiment by placing the bulb in the focus of a spherical tin reflector about six inches diameter: by this means the source of heat could be placed at a sufficient distance to preclude any effect from the glass screen.

(18.) The experiment was again varied by placing a large opake screen before the instrument, in which was an aperture through which one bulb might be exposed. 'To this aperture a piece of glass could be applied. Each bulb was presented both with and without the glass.

(19.) In all these experiments it is evident, that any heating effect arising from the screen would tend to diminish the ratio of the black and white effects; and this not being allowed for in the statement of the result, the difference between this ratio 


\section{Mr. B. Powell's experimental Inquiry into the Nature}

and that of the exposed effects will be in reality greater than appears.

The results are comprised in the following table:

(20.) Lamp. Bulb in the focus of a reflector. Coatings, white silk and Indian ink.

\begin{tabular}{|c|c|c|c|c|}
\hline \multirow{2}{*}{$\begin{array}{c}\text { Experi- } \\
\text { ments. }\end{array}$} & \multicolumn{2}{|c|}{ Screened. } & \multicolumn{2}{c|}{ Exposed. } \\
\cline { 2 - 5 } \cline { 4 - 5 } & White. & Black. & White. & Black. \\
\hline 1 & 5 & 8 & 11 & 15 \\
2 & 4 & 9 & 13 & 15 \\
3 & 6 & 11 & 12 & 14 \\
\hline Mean in 30 & sec. 5 & $9 \cdot 3$ & 12 & 15 \\
\hline
\end{tabular}

Incandescent iron.

\begin{tabular}{|r|l|l|l|l|}
\hline 1 & 4 & 7 & 11 & 13 \\
2 & 4 & 6 & 10 & 10 \\
\hline Mean & 4 & $6 \cdot 5$ & $10 \cdot 5$ & $11 \cdot 5$ \\
\hline
\end{tabular}

(22.) Lamp. One bulb covered by an opake screen, the other exposed at an aperture. Distance 5 inches. Screen 1.5 inch from bulb.

\begin{tabular}{|c|c|l|l|l|}
\hline 1 & 4 & 6 & 8 & 11 \\
2 & $3 \cdot 5$ & 6 & $9 \cdot 5$ & 12 \\
3 & 4 & 6 & 8 & $10 \cdot 5$ \\
4 & 3 & 6 & 8 & 12 \\
\hline Mean in 1 min. 3.6 & 6 & $8 \cdot 3$ & $11 \cdot 3$ \\
\hline
\end{tabular}

Incandescent iron.

\begin{tabular}{|l|l|l|l|l|}
\hline In 30 sec. & 3 & 4 & 12 & 9 \\
\hline
\end{tabular}

(24.) It is, perhaps, not worth while to make any formal deductions from these results as to the ratio subsisting in the different cases. It will be sufficiently evident upon inspection, that, when all due allowances are made, the ratio of the effects upon the white and black bulbs is considerably greater when they were affected only by the transmissible part of the heating effect, than when they were exposed to the whole. 'The part, then, which is added on the removal of the screen, is of a nature tending to add to the terms of the former ratio quantities in a ratio much nearer equality: quantities in a ratio very nearly that which the effects of simple radiant heat would give.

III. (25.) 
III. (25.) I have above adverted to all the sources of error which occur to me as likely to have affected these results; and when these are taken into consideration, as well as the nature of the experiments and apparatus, the accordance with the different results exhibited is perhaps as close as we can expect: and it appears that all the different sets of experiments agree in showing a very considerable difference in the ratio of the effects produced on a smooth black and on an absorptive white surface, by that part of the radiant effect transmitted through glass, and by the total effect. If the total direct effect were the result of one simple agent, the intervention of the glass would, by intercepting some part of it, produce no other alteration than a diminution of intensity; the ratio of the two effects would remain unchanged. This distinction appears to me of some importance towards clearing our ideas respecting the nature of the phænomena, and thus affording an answer to the question originally proposed in reference to some theoretical views, which, though boasting the sanction of high authority, will be untenable if the validity of these results be admitted.

(26.) The general conclusions from all these experiments may be thus recapitulated:

Ist. That part of the heating effect of a luminous hot body which is capable of being transmitted in the way of direct radiation through glass, affects bodies in proportion to their darkness of colour, without reference to the texture of their surfaces.

2nd. That which is intercepted produces a greater effect in proportion to the absorptive nature of texture of the surface, without respect to colour. These two characteristics are those which distinguish simple radiant heat at all intensities.

Thus then, when a body is heated at lower temperatures, it gives off only radiant heat stopped entirely by the most transparent glass, and acting more on an absorptive white surface than on a smooth black one.

At higher temperatures the body still continues to give out radiant heat, possessing exactly the same characters. But at a certain point it begins to give out light: precisely at this point it begins also to exercise another heating power distinct from the former, -a power which is capable of passing directly through transparent screens, and which acts more on a smooth black surface than on an absorptive white one.

(27.) This last sort of heat, whatever its nature may be, is essentially different from simple radiant heat. It appears to agree very closely with what the French philosophers term calorique lumineux, and is, according to Professor Leslie's 
theory, a conversion of light into heat. These views of the subject are certainly gratuitous assumptions. We have no right whatever to identify those two agents, or to suppose that, because a heating effect very closely accompanies the course of the rays of light, the light is therefore converted into heat : but the theories above alluded to seem to regard the whole heating effect of a luminous body as of this latter character. In this particular, the present inquiry has led us to an essential distinction; and if the experiments are to be relied upon, this peculiar sort of heat constitutes only a part of the total effect. These results do not indeed present so simple a theory as that alluded to, but they apply very obviously to the explanation of many phænomena recorded by various experimenters.

(28.) The peculiar heat above spoken of, and which for the sake of distinction and brevity we may call "transmissible heat," is similar to that which acts in the solar rays, and which there constitutes the total effect. It is this kind of heat which has been employed as a principle of photometry, on the assumption that it is precisely proportional to the intensity of light. Within certain limits this may be the case; but there are unquestionably circumstances under which the relation is very different; such, for example, as difference of colour in the light: and in general it cannot be assumed to hold good in light from different sources. To show this, there is a remarkable instance in incandescent metal, which produces but very faintly illuminating rays, yet its "transmissible heat" is very considerable. I have repeatedly tried the experiment with a small "photometer," having one bulb painted with Indian ink and the other plain: the bulbs being in a vertical line, this instrument, whether employed with or without its case or a glass screen, always gave an effect of about $10^{\circ}$ in $30^{\prime \prime}$ at eight inches distance from a ball of iron heated to the brightest point in a common fire.

(29.) In making these last experiments, the effect was always greater when the instrument was used without its case or a glass screen. This was no doubt in part owing to the greater action of the simple heat now admitted to the instrument on the coated than on the plain bulb; but it was also in part occasioned by the circumstance, that the stem going to the upper bulb passes in contact with the lower, and being a solid mass compared with the thin bulb, is slower in acquiring heat, and therefore cools it, - thus increasing the apparent effect on the other.

(30.) In a variety of other experiments which I have tried, using either this "photometer," or another having the bulbs at equal heights, various apparent anomalies presented them- 
selves; all which I found easily explained on the principles here established of two radiations, when connected with the various other considerations to which it is necessary to refer when employing instruments of this description : but I do not conceive it necessary to enter into any further details.

\section{On the Osteology of Reptiles, and on the Geological} Position of their Fossil Remains. By M. Le Baron G.CvVIER*.

MY work has necessarily resolved itself into a sort of treatise on comparative osteology, since I have been constantly obliged to bring under consideration, together with fossil bones, those of living species; nor could I have detected the differences which exist among them, otherwise than by employing figures and detailed descriptions for this purpose: but every labour devoted to the ascertainment of the differences in the productions of nature leads to the developement of their particular relations ; and, indeed, the reader will have had no difficulty in perceiving that, notwithstanding the so greatly varied proportions which belong to these bones, and notwithstanding the exterior forms (often of so extraordinary a description) which hence result, there exists nevertherless, throughout the mammiferous tribes, a sort of common or universal plan, a composition nearly the same, and of a nature to enable us always to recognise each bone, by means of its use and position, through the whole of the metamorphoses under which it passes, and in spite of the difficulty presented in this recognition by the enlargements or diminutions of size which it may have undergone. Thus, in the figures of the heads which we have given, may be traced, from Man to the Whale, the frontal bones, the parietal bones, the bones of the nose, -in a word, the whole of the parts constituting of the cranium and face, with very few exceptions; such as the absence of the lachrymal bones in some species, and perhaps the inter-parietal in others. The remaining apparent differences in the number of the bones arise in general from the greater or less promptitude, or perfection of continuity,

* From the author's Recherches sur les Ossemens Fossiles, vol. v. part 2. -We hope to present our readers, in continuation of this article (which contains the preliminary observations on the fossil remains of reptiles, ) with a series of translations from the same work, respecting the Saurian reptiles, illustrated with engravings. M. Cuvier's Memoirs on the Osteology of living and fossil Elephants, (another interesting branch of his work, have already been given in the Philosophical Magazine, vols. xxvi.-xxx.-EDrT. 